\title{
Educação e Contemporaneidade em Michel Serres ${ }^{1}$
}

\author{
Maria Emanuela Esteves dos Santos* \\ http://dx.doi.org/10.1590/0103-7307201507615
}

Foi em clima informal e de amistosa receptividade que o filósofo Michel Serres nos acolheu para dois dias de entrevista na França em janeiro de 2014. O primeiro deles em Paris, em um Café na Place de la Sorbonne; e o segundo em sua agradável residência em Vincennes. A acolhida afetuosa foi muitas vezes reafirmada em razão da simpatia pelo Brasil e pelos brasileiros, que o filósofo frequentemente evocava. Serres ressaltou, em muitos momentos, as lembranças carinhosas que tinha do Brasil, do período em que ele deu aulas em São Paulo, na década de 1970; da cultura brasileira que ele muito apreciava; e dos amigos que ele cultivou aqui.

Nascido em 1930, em Agen, no sul da França, cursou matemática na Escola Naval Francesa e filosofia na Escola Normal Superior de Paris, tendo sido aluno de Canguilhem. Defendeu em 1968 sua tese de doutorado sobre Leibniz e, nesse mesmo ano, participou da criação da Universidade de Vincennes com Michel Foucault, onde trabalhou como historiador das ciências. No mesmo período, foi professor também na Universidade de Clermont-Ferrand. Pela impossibilidade de trabalhar com filosofia na França, aceitou ser professor nos Estados Unidos, onde atuou nas universidades de Baltimore, Buffalo, Nova York e, a partir de 1980 até 2013, em Stanford.

Autor de mais 60 livros publicados ao longo de 50 anos de trabalho, Serres ocupa, no entanto, uma posição ambivalente no espaço público e intelectual. Na tentativa de trabalhar a língua como um poeta, sem, contudo, perder o rigor e a precisão dos saberes, a produção de Serres ou seus conceitos filosóficos seguem
* Faculdade de Educação, Universidade Estadual de Campinas - UNICAMP, Campinas, SP, Brasil; Université de Rouen, Rouen, France. manu_esteves@ yahoo.com.br

1. Pesquisa financiada pela Fundação de Amparo à Pesquisa do Estado de São Paulo - FAPESP. 
pouco conhecidos, ao menos na França e no Brasil. Conhecem-se, muitas vezes, seus discursos de orador ou suas exposições claras e assertivas de professor, mas pouco se conhecem seus conceitos filosóficos. Para descobri-los não basta ouvi-lo ou acompanhar uma ou outra apresentação sua que circule nas mídias. É nos seus textos escritos, no estudo das suas muitas obras publicadas que se pode descobrir o curso do seu pensamento, suas ideias e suas proposições. E isso não deixa de ser um desafio diante da extensão e diversidade da obra e da peculiaridade no estilo do autor. Desafio que se confronta, sobretudo, com a presumida impossibilidade de conciliação entre a magia e a beleza da palavra e o rigor conceitual de um pensamento. Serão mesmo inconciliáveis? Serres nos ajudou a traçar algumas linhas que podem nos ajudar nesse percurso, impulsionado pelo tema educação.

MARIA EMANUELA - Eu acredito que o senhor pode nos ajudar muito a pensar a educação, sobretudo hoje, a partir de uma teoria da multiplicidade. Se o senhor me permite, eu gostaria, portanto, de começar por essa grande questão: para o senhor, o que é educar? MICHEL SERRES - Eu creio que há muitas respostas para essa questão. A primeira resposta seria a diferença, em língua francesa, entre educar (éduquer) e instruir (instruire). Instruir é simplesmente dar a informação sobre um conhecimento. Isso é um problema bem fácil, porque se trata de ciência, de conhecimento, como a matemática, a gramática, etc. Isso é simplesmente o conhecimento: instruir. Obviamente, isso não é educar. Educar é formar a pessoa em geral. Logo, por que eu sou interessado nesse problema sobre instrução e educação? É que uma certa cultura estava se modificando quando eu escrevi Filosofia mestiça (1993) e quando eu escrevi Polegarzinha (2013). E o que se modificou? Começando do final, da mais recente possível, a Polegarzinha, o que mudou completamente na educação foi a minha relação com a geração que eu ensinei. Por quê? Porque, quando eu ensinei há 20 ou 30 anos, meus estudantes não conheciam a 
resposta para a questão que eu colocava. Hoje, quando eu entro em uma sala ou em um anfiteatro, muitos dos meus estudantes já digitaram na internet o tema do meu curso. Em consequência, há uma diferença entre os meus estudantes de hoje e os meus estudantes de 20 ou 30 anos atrás, e essa diferença está simplesmente no acesso à informação. 0 acesso à informação é hoje imediato, fácil e disponível a todo mundo pelas novas tecnologias, pela internet, etc. De tal modo que nós não sabemos hoje que forma terão futuramente a escola, a universidade, os centros de pesquisas, etc. Tudo isso simplesmente porque há uma movimentação de acesso à informação. E isso é uma questão realmente muito, muito importante no mundo hoje, porque a diferença no acesso à informação mudou completamente o jogo do ensino. Essa é a primeira resposta que eu posso dar a sua questão.

M-E - É possível fazer uma educação sem instrução? Ou as duas se necessitam?

MS - Não. Eu não acredito. Eu penso que elas são muito diferentes, porque uma concerne ao saber e a outra à pessoa em geral, mas não se pode fazer essa ruptura, porque não há educação sem instrução, de nenhuma forma. Observe, por exemplo, a educação física, o professor de ginástica. Bem, poder-se-ia dizer num primeiro momento que o professor de ginástica não tem um saber específico. Mas, claro, há um saber, sim. É preciso saber fazer tal gesto, é preciso saber pegar a raquete e fazer um reverso ou um movimento à direita, por exemplo. É preciso saber alterar um salto, etc. Não, não. Em toda educação há a instrução, de alguma forma.

M-E - Muito bem. 0 senhor disse que há uma diferença entre educação e instrução e que há hoje uma mudança no acesso à instrução. E na educação, é possível pensar de que forma essa mudança vai alcançá-la? MS - Isso é um pouco ligado, por uma razão bem simples. Quando você pega uma ferramenta, um automóvel, etc., há a maneira 
de se servir dessa ferramenta, mas por outro lado, há o mundo inteiro que está implicado nela. Por exemplo, eu, que sou velho, me sirvo do computador. Eu me sirvo do computador como se ele fosse uma ferramenta. Já as minhas crianças, os meus estudantes, estão no mundo do computador. É, portanto, a pessoa que muda. E, em particular, eu creio que é possível notar hoje uma diferença de relação com o conhecimento, da relação corporal, da relação vital e da relação pessoal com o conhecimento. Uma verdadeira diferença. Isso quer dizer que - você conhece as ciências cognitivas, evidentemente? - as ciências cognitivas pensam hoje que não são as mesmas zonas do cérebro, os mesmos neurônios que são tocados, excitados por uma página de papel ou por uma tela interativa, sim? Portanto, é a pessoa inteira que se reorganiza. Uma disposição afeta o conhecimento, mas afeta também a pessoa e o mundo inteiro onde ela vive.

M-E - Na questão sobre o que é a educação, o senhor disse inicialmente - e eu estou totalmente de acordo - que há várias respostas, porque essa é uma questão muito abrangente. Nesse sentido, o senhor disse que a primeira coisa que poderíamos pensar é a diferença que há na língua francesa - e em português também - entre educação e instrução. Contudo, o senhor disse que há muitas respostas. Essa seria a primeira. 0 senhor poderia dizer quais outras respostas nós poderíamos pensar? Quais são outros elementos para se pensar o que é a educação?

MS - Eu me recordo que, quando eu era criança, o mundo estava em guerra e havia poucos professores. Todos partiram para as batalhas. Foi necessário então mudar as classes. Eu estava na classe dos mais novos e me colocaram na dos mais velhos. Me fizeram avançar algumas classes porque faltavam professores. E, como eu estava no primário, eu sabia apenas o que era a aritmética: um, dois, três, a adição, a subtração. No entanto, como me fizeram avançar algumas classes, de repente o professor que era professor de matemática - escreveu $x$ no quadro, $x$... "ele 
conta com letras e não com números?”, pensei. E em seguida ele escreveu $x$ e $y$. Era a família das incógnitas. "O que é que ele estava fazendo?” Então, eu levantei o dedo e perguntei: “o que quer dizer $x$ ?" Ele me disse: "é a incógnita”. “Incógnita? 0 que é incógnita?". Sim, ele me disse, "é uma letra que contém todos os números possíveis". E de repente eu fui iluminado. Foi como se o céu se abrisse quando eu me dei conta que se podem conter todos os números de uma só vez. Um pouco como se você tivesse não só um cruzeiro, dois cruzeiros, três cruzeiros, etc., mas uma bolsa com todos os cruzeiros possíveis. E com essa bolsa eu me dei conta, “ah!”. Eu tinha encontrado o abstrato. Você compreende? E eu me recordo disso como uma das maiores alegrias da minha vida. Era uma situação muito difícil. E de repente, a Maria Emanuela que está diante de mim, ela entende o que eu digo, os olhos dela brilham, a sua mente está iluminada, ela compreende, ah! Assim, ensinar é favorecer essa alegria. É isso. Você abre a porta e você entra em outro mundo. Ensinar é isso. É promover o êxtase. Por um momento não se está no mundo, se encontra outro mundo. É isso, você compreende? Por exemplo, um dia me pediram para explicar o infinito para pessoas que não tinham nenhuma instrução. E eu de repente, ao explicar, vi uma mulher diante de mim e parecia que ela estava no paraíso. Ela havia compreendido. Assim, o orgasmo. Exatamente. Então, ensinar é promover o êxtase, o orgasmo.

M-E - Compreendo. 0 senhor continuou a publicar muito nos últimos 20 anos, de tal forma que Polegarzinha e Filosofia mestiça não só estão longe uma da outra temporalmente, como há entre elas várias outras obras. Nesse caso, Filosofia mestiça é ainda o seu livro sobre educação? Ele continua a ser o seu livro sobre educação depois de 20 anos?

MS - Interessante que esse é um livro que eu escrevi não muito longe da minha viagem ao Brasil. Vejamos bem, em Filosofia mestiça eu abordei a educação como uma noção de mestiça- 
gem. Eu disse que, quando eu aprendo inglês, eu me torno um pouco americano ou inglês; quando eu aprendo português, eu me torno um pouco português ou um pouco brasileiro; quando eu aprendo espanhol, eu me torno um pouco madrileno ou mexicano; e assim por diante. Mas quando eu aprendo matemática, eu mudo também a pessoa; quando eu aprendo história, meu corpo, minha personalidade muda, e consequentemente se transforma o processo da aprendizagem em um processo de mestiçagem. E eu me lembro que, quando eu cheguei ao Brasil, a noção do mestiço, na qual a sua língua tem uma riqueza extraordinária, estava totalmente em harmonia com uma discussão que acontecia no país. Um país onde há muita contribuição de genealogia para testemunhar que uma mestiçagem é, evidentemente, uma forma de cultura. E então havia uma harmonia curiosa e incompreensível para mim entre minha ideia de aprendizagem e o que aconteceu culturalmente no Brasil. Eu o disse em Filosofia mestiça, de maneira mais técnica - por uma questão que me toca particularmente durante toda a minha carreira -, que dentro da universidade se divide de forma muito rigorosa: as ciências exatas e as ciências humanas, e essa divisão é catastrófica, na minha opinião. Isso quer dizer que nós formamos, de um lado, instruídos completamente incultos e, de outro lado, pessoas cultas completamente ignorantes. Então minha ideia em Filosofia mestiça era de reunir precisamente; mestiçar precisamente o que se sabe das ciências exatas e o que se sabe das ciências humanas, porque, sempre quando praticamos as ciências humanas sem conhecer as ciências exatas, nos expomos a enormes erros. E, reciprocamente, quando você é um engenheiro, por exemplo, e você impõe um tal tipo de técnica sobre um terreno, mas você não conhece a etimologia, a psicologia, a sociologia que envolvem o terreno em questão, você faz barbaridades. Dessa forma, o meu "terceiro instruído" era por essa mestiçagem entre as ciências exatas e as ciências humanistas. É isso. 
M-E - Como podemos pensar a ligação entre a sua concepção sobre educação, que parece ser uma concepção geral, e talvez intemporal, a partir de Filosofia mestiça e as condições de um tempo e um espaço específicos? Há algo que persiste nos diferentes tempos e espaços, por exemplo, a ideia de um certo humanismo, a ideia de paz? $0 u$, como fazer a passagem entre a concepção geral e as condições específicas?

MS - Mais precisamente, tanto Filosofia mestiça quanto o que eu fiz até agora consistem exatamente em se adaptar às circunstâncias do tempo. Então, há duas coisas: as circunstâncias do tempo e as circunstâncias do espaço, como você disse. Eu vou começar pelo espaço. Há justamente um teorema matemático recente que resolve a questão. Com uma combinação qualquer de código de telefone, qualquer um que esteja ou que habite São Paulo, por exemplo, pode entrar em contato por acaso com uma pessoa que mora no Japão ou em Paris. Hoje, com alguns códigos de telefone, qualquer um no planeta pode chamar qualquer outro no planeta. E os que descobriram esse teorema estatístico o chamam "teorema do mundo pequeno". Então, do ponto de vista espacial, nós somos, doravante, todos vizinhos. Veja, isso quer dizer que, quando eu tenho um telefone, eu posso falar com uma pessoa que eu nem sequer conheço. Portanto, você é minha vizinha, mesmo se você habitar Minas Gerais, percebe? Há hoje uma nova concepção de vizinhança - virtual, é claro -, mas uma nova concepção de vizinhança que dá ao mundo atual um novo perfil. $\mathrm{E}$, consequentemente, a sua questão sobre o geral e o particular está se modificando. Porque, precisamente, essa vizinhança torna-se - mesmo que virtual - também real. É por isso que as tecnologias e o uso delas me interessam. Eu posso chamar não importa quem, não importa onde. Ele é meu vizinho. E então velhos avós não estão contentes porque dentro do metrô há alguém que telefona. E eu digo a ele: "você que está ao lado dela, você não é seu vizinho, você nem ao menos fala com ela". Isso quer dizer que aquele com quem ela fala daqui de Paris pode estar agora, 
por exemplo, em São Paulo, mas é seu vizinho. Assim, o vizinho real não é mais vizinho e o vizinho virtual tornou-se vizinho. Seria uma nova passagem de proximidade. Então, isso não acontece obviamente em relação à cultura local. Você continua a falar a sua língua, a ter tais hábitos, tais usos, eu também, etc. Há uma nova vizinhança e não podemos educar as pessoas, esquecendo essa novidade. Ela é uma verdadeira novidade.

M-E - Falamos sobre o espaço. E sobre o tempo? Há também condições que são específicas de um tempo. A educação no século $\mathrm{V}$ a.C., por exemplo, e a educação hoje. Nós podemos pensar que o conceito que temos de educação como mestiçagem se aplica tanto ao século $\mathrm{V}$ a.C. quanto a hoje? Trata-se do mesmo conceito nesses dois momentos?

MS - Sim e não. A palavra "pedagogia" veio da palavra grega paideia, e esta foi inventada justamente no mesmo momento em que se inventou a escrita. Na educação, em outros momentos, se tinha apenas a palavra - alguém que cantava ou falava, e era preciso repetir o que ele dizia. Desde o momento que se inventou a escrita, cada estudante podia ter diante dos olhos algum registro do que era ensinado. Logo, a pedagogia mudou, a escola mudou, a partir do instante que houve a escrita. Obviamente, a escola mudou completamente quando surgiu o livro. Por exemplo, se diz que, no momento da Reforma, Lutero afirmava "todo o homem se torna um papa com uma bíblia na mão”. Após o livro, não era mais necessário o papa, se estava diretamente ligado a Deus. Portanto, observe, tudo se modifica com a invenção técnica da escrita, da leitura, etc. e do digital da Polegarzinha. Por outro lado, a ideia que compõe uma relação pedagógica entre o mestre e o aluno é constante na história. 0 mestre pode ser um aedo, um cantor, um professor, etc. $\mathrm{O}$ suporte modificou-se de forma definitiva, o suporte escrito, o suporte livro ou o suporte digital. E eu acredito que é por isso que se trabalha em filosofia da educação, porque há uma nova condição. É preciso inventar. Não há dúvidas. 
M-E - Como o senhor disse, há uma relação entre educação e instrução. Com a passagem do tempo, os instrumentos, as técnicas de acesso à informação se modificam. Consequentemente, há uma mudança também na educação, uma vez que a forma de obter a informação se modifica. Nós podemos pensar, então, que a educação como mestiçagem é uma educação específica do nosso tempo?

MS - Ela sempre esteve mais ou menos lá, porque a cultura transmitida pela educação sempre permite um certo tipo de compreensão do outro. Mas hoje, no entanto, com o fato de você ter uma relação com o seu celular, com não importa quem no mundo, isso vai de toda forma nos adaptar bem mais uns aos outros. Isso quer dizer, é possível, hoje, que a educação tal qual nós a praticamos, tal qual nós a inventamos, seja talvez uma possibilidade de paz bem mais importante que em outros tempos. Uma possibilidade de paz. Ou seja, meus filhos têm hoje tantas relações com alemães, com italianos, com ingleses, etc. Eu não sei como uma guerra seria possível assim. Você compreende? É, de qualquer maneira, alguma coisa que avançou na educação possível. Então, não mais no sentido da instrução, mas no sentido do humanismo.

M-E- A grande contribuição da sua filosofia consiste em ser um pensamento sobre a multiplicidade. Como compreender esse pensamento no qual você se engaja?

MS - Então, para compreender a multiplicidade, eu vou te propor uma imagem. Você veio a Paris e o símbolo de Paris conhecido por todos é a Torre Eiffel. Todo mundo conhece a Torre Eiffel. Então, permita que eu a desenhe. Ela tem um ponto muito agudo no alto e depois ela se alarga na base como uma pirâmide, uma pirâmide do Egito. Portanto, há um no ponto agudo no alto e múltiplos no ponto mais largo. A civilização de hoje é a Torre Eiffel. Isto é, você escuta a rádio, há um que fala e muitos que escutam. Você assiste à televisão, há um apresentador que fala e muitos que escutam. Você tem um presidente do Brasil e muitos sujei- 
tos. Assim, tudo é constituído sobre o modelo um/múltiplos. E a questão é que lá no ponto agudo há poder, riqueza, informação. Todo mundo que escuta a televisão observa aquele que fala como se ele fosse o bom Deus, é isso que eu quero dizer. Então, a civilização da multiplicidade é esquecer a Torre Eiffel. Eu pedirei que, por um breve momento, esqueçamos a Torre Eiffel. 0 essencial é observar o que se passa na base da Torre Eiffel. Esqueça completamente o ponto agudo. E assim, de certa maneira, se dá uma nova ideia de educação, de política, de mídia, etc. Então, por que eu digo multiplicidade? Eu volto agora à Polegarzinha. A Polegarzinha pega o celular. Você conhece em francês o adjetivo de tempo ou o advérbio que se denomina maintenant? Como se diz em português? "Agora”, correto. E agora quer dizer, agora eu estou falando com você, eu posso te tocar, você está diante de mim..., mas em francês não se diz isso. Se quer dizer mão (main) tendo (tenant). Maintenant, ela tem em suas mãos. E então, o que ela tem em suas mãos? Ela tem em suas mãos, eu te digo, todas as informações que ela gostaria. Eu gostaria de saber a população do Brasil, pesquiso no celular, pronto: eu sei. Eu gostaria de saber qual a riqueza de uma tal mina em Minas Gerais, eu sei. Eu gostaria de saber a sua idade, eu sei. Tudo. Primeiramente, informação. Em segundo, ela pode conhecer todos os lugares. Onde você mora? Qual o endereço? Eu procuro no Google e eu posso ver até mesmo a fotografia da sua casa, atrás, a frente, a porta, e mesmo, possivelmente, a sua sala de jantar. Portanto, eu tenho todas as informações, todos os lugares, mesmo se eu jamais tenha lhe falado. Por outro lado, eu posso chamar com alguns códigos de telefone não importa quem no planeta. Consequentemente, maintenant, eu tenho nas mãos o mundo. E eu vou agora te fazer uma pergunta: quem na história podia dizer "agora eu tenho nas mãos o mundo"? Quem? Sempre, quem estava na ponta da Torre Eiffel: Luiz XIV, Napoleão, a rainha da Inglaterra, um milionário americano... $\mathrm{E}$ agora todo mundo que está na base da Torre Eiffel pode dizer. Todo mundo. Todo mundo 
tem nas mãos o mundo, e isso é uma novidade extraordinária. Isso quer dizer: a teoria da multiplicidade é o fim da Torre Eiffel. A utopia democrática, por excelência, é a utopia democrática. Todo mundo - você, ela, ele - tem nas mãos o mundo. Todo mundo é Napoleão. Você é Napoleão. Todo mundo é Napoleão. Isso é a novidade, a novidade real.

M-E - A referência à "Passagem do Noroeste", como alusão à relação difícil, mas necessária, entre a ciência e a cultura, é um elemento muito importante na sua filosofia, em particular em Filosofia mestiça. Como o senhor pensa essa passagem hoje? Podemos pensar que as condições de nosso tempo, que engendra a geração Polegarzinha, pode facilitar essa passagem, assim como a fonte de gelo do polo se torna hoje mais fluida. A geração Polegarzinha pode dissolver as fronteiras e fazer dessa passagem um caminho menos tortuoso? Qual a relação de Polegarzinha com o saber?

MS - Então, na sua pergunta há duas questões. A primeira é a “Passagem do Noroeste”, e a segunda é Polegarzinha. Primeiramente, em relação à passagem em questão, desde que eu escrevi a Passagem do Noroeste (1980), eu propus uma nova ideia, que eu chamo A grande narrativa. E A grande narrativa tornou-se possível desde que as ciências começaram a datar os objetos. Desde que aquele que se ocupa da cosmologia me disse que o Big Bang aconteceu há quinze bilhões de anos; que aquele que se ocupa da geofísica me disse que o planeta começou há quatro bilhões de anos; que os biologistas me disseram que a vida começou no planeta Terra há três bilhões e oitocentos milhões de anos; que o historiador, ou naturalista, me disse em qual data diferentes espécies surgiram ou desapareceram, eu pude religar todas essas ciências em conjunto e fazer uma grande narrativa que começa no início do universo, o resfriamento do planeta, o início da vida, o desenvolvimento dos seres vivos, a evolução, o surgimento do homem e assim por diante. Eu tenho uma grande narrativa. $\mathrm{E}$ essa grande narrativa é uma verdadeira Passagem do Noroeste. 
Ela nos permite passar de uma ciência à outra: de uma ciência do mundo para uma ciência da vida e de uma ciência da vida para uma ciência do homem. Consequentemente, a grande narrativa sobre a qual eu falo no meu último livro (Les temps nouveaux, 2013) é uma nova Passagem do Noroeste. E, consequentemente, à medida que eu trabalhava, eu podia pontuar coisas bem precisas. Dessa forma foi possível fazer um programa de educação a partir da grande narrativa. Há até mesmo um livro que eu escrevi que se chama $O$ incandescente (2005); no final do livro eu apresento um programa de educação a partir da grande narrativa. Aí está. Essa é a primeira questão. A segunda questão é evidentemente sobre a Polegarzinha. Sobre a Polegarzinha há um elemento novo que chegou recentemente sobre toda essa questão e do qual eu falei agora há pouco. É que com um telefone celular acessa-se direto a informação. E esse acesso direto à informação é totalmente novo. Eu, quando tinha sua idade e eu não morava em Paris, se eu quisesse uma informação científica, era necessário que eu pegasse o trem, que eu passasse a noite no trem, que reservasse um hotel em Paris, que eu conseguisse um registro na Biblioteca Nacional, que eu passasse ali oito dias e enfim, eu teria a informação. Isso me demandava oito dias e muito dinheiro. Hoje, em alguns segundos, eu tenho a informação. Isso muda completamente a relação com o saber. Mas, atenção! Há uma diferença entre informação e saber. Eu posso clicar e ter uma informação, por exemplo, sobre física quântica, mas eu não vou compreender nada. Nesse caso, eu tenho a informação, mas não tenho o saber. Logo, eu preciso de alguém que me ensine. Consequentemente, essa questão sobre a Polegarzinha, sim, ela dissolve as fronteiras, não pela grande narrativa que eu mencionei há pouco, mas pelo acesso direto à informação. Ela pode acessar qualquer informação. É essa a diferença.

M-E - 0 senhor dedica a sua filosofia a pensar diversos assuntos que são cada vez mais importantes para a nossa sociedade. No entan- 
to, me parece que o senhor faz esse trabalho ao preço de uma certa incompreensão de uma parte de seus pares - acadêmicos, entre outros. Como o senhor vê esse tipo de incompreensão? Ela se poderia explicar pela busca por uma maior coerência com sua filosofia? $0 u$ ainda, por uma postura de escritor na sociedade - caso o senhor se considere um escritor que não escreve segundo as normas universitárias habituais?

MS - Eu sou um acadêmico, eu me formei na universidade, na École Normale. Eu passei no concurso, eu ensinei filosofia na universidade, e a norma universitária me parece excelente. Isto é, ela se consagra ao saber, à honestidade, à clareza e à referência aos autores. É uma norma muito, muito boa. Toda a questão que eu me coloquei quando eu deixei o modelo universitário é que esse modelo estava, na minha opinião, muito orientado em direção ao comentário, sobretudo em filosofia. Reconhece-se como filósofo somente aquele que citou Nietzsche, Marx, Descartes, Platão, etc. Então, havia uma chuva intensamente importante de citações. E eu tentei sair desse modelo, por quê? Porque minha preocupação, num certo momento, foi de compreender a novidade que acontecia em nosso tempo. E a novidade que acontecia em nosso tempo afetou duas coisas: primeiramente as ciências e, posteriormente, o efeito das ciências na sociedade. Ora, na minha vida eu assisti a três, quatro, cinco grandes revoluções. As matemáticas mudaram, a física mudou, a química mudou, a biologia mudou. Todas as ciências se transformaram. Havia a matemática moderna, a física da informação, a bioquímica, a biologia com todo o problema ético que ela colocava. Havia todos os problemas morais que se colocavam as ciências. Ora, eu me encontrava diante de um problema que era verdadeiramente muito decisivo para mim, visto que a norma universitária me impedia de ver essas mudanças. E eram essas mudanças que me interessavam, compreende? Então, eu tentei, evidentemente, dar lugar na minha filosofia para as revoluções científicas, revoluções biológicas, revoluções, etc. E então, por último, sobretudo, as 
revoluções informáticas e digitais. E não há citação de filósofo na história que me permita compreender o digital. Portanto, é necessário que eu invente ferramentas intelectuais novas para compreender a era contemporânea.

M-E - A formação curricular ou a formação disciplinar é frequentemente sujeito de debates e de proposições no pensamento educacional. Falamos muito hoje de uma formação interdisciplinar e nos esforçamos aqui e ali por oferecer uma formação menos especializada e mais completa. No entanto, me parece que, se partirmos do conceito multiplicidade, é possivel pensar a relação entre os diferentes saberes, bem como uma educação para essas relações, resguardando, de certa forma, a noção de rigor disciplinar. Nesse caso, trata-se de criticar as noções de rigor e de disciplina, que parecem interligadas, ou trata-se de pensar de uma outra forma esse rigor? Se sim, de que forma? Como, dizendo de outra maneira, as perspectivas de Filosofia mestiça podem ser relacionadas às noções de currículo e de formação disciplinar?

MS - Essa é uma questão sobre a qual eu já refleti muito e eu não estou certo de ter uma boa resposta. Isso é muito difícil. É muito difícil porque, de fato, devemos ser rigorosos e precisos quando temos uma especialidade bem definida. Chamamos isso de honestidade da formação universitária e disciplinar. Quando você é especialista em uma questão, você a pensa de uma forma precisa, rigorosa, etc. Então, evidentemente, toda a questão é de relação. A invenção é sempre uma questão de relação. Eu te dou um exemplo. Havia a astronomia no começo do século XX e havia a física. $E$ de repente houve astrônomos e físicos que entraram em relação e inventaram a astrofísica. Isso representou uma novidade extraordinária e uma nova disciplina. Da mesma forma, havia químicos e biologistas, eles inventaram a bioquímica. Era uma nova disciplina. Assim, efetivamente, no começo da relação perdemos um pouco da precisão, ou do rigor, mas a chance é de inventar uma nova disciplina que terá, por ela mesma, um novo 
rigor. Todavia, eu não sei muito bem como se escapa do antigo rigor e se inventa o novo. Sim, é essa a questão. Portanto, eu acredito que é preciso, de fato, se dedicar a estudos interdisciplinares, mas como gerir a questão do rigor e da precisão? Eu me esforço para responder à questão. É muito difícil.

M-E-É uma questão para se pensar. Uma questão muito interessante. MS - Sim. É talvez a diferença que há entre a educação e a invenção. É essa, eu acredito, a verdadeira resposta. Isto é, eu posso estar, por exemplo, na biologia, é necessário que eu pense realmente o que é uma espécie viva, o que é um indivíduo, o que é uma planta. E aí há precisão, descrição, etc. E se eu me jogo, de repente, numa relação com outra disciplina, eu perco essa precisão. Portanto, há, de um lado, a formação e a educação; e, de outro lado, a invenção, a inovação. Isso é um pouco a questão que você me fez: por que o senhor deixou o modelo universitário? Eu te disse que ele era bom, honesto, preciso, rigoroso, que eu gostava muito dele, mas que eu o deixei, pois eu precisava ver o novo.

M-E - É necessário, portanto, partir.

MS - É isso. Forme-se bem, seja rigoroso, seja preciso, seja honesto, mas, em um certo momento, ops!, é necessário que você saia, se você quiser inventar. É isso.

M-E - Especificamente sobre o Brasil, há um mito ou um clichê no qual se pensa ter havido uma harmonia na relação entre as diferentes culturas que o constituíram. Há, sim, uma mestiçagem, mas há também muitos conflitos. Esse mito veio acompanhado, durante um tempo, de uma falsa convicção de que no Brasil não há preconceitos raciais. Hoje, essa falsa convicção é questionada, e nós falamos de um preconceito velado que marca a nossa sociedade. A consciência desse fato foi benéfica para nos ajudar a enfrentar o problema. Falamos sobre preconceito e pensamos sobre essa questão. Em nossa 
sociedade nós começamos a ver o outro e as relações que temos com ele. Então, essa situação nos faz refletir: a mestiçagem só é possível quando eu sou capaz de reconhecer no outro uma alteridade? É preciso que eu veja o outro e o reconheça em sua alteridade. Mas, ao mesmo tempo, não seria essa relação também uma violência, como propõe, por exemplo, a ideia de antropofagia? Ou seja, é possível fazer uma relação entre mestiçagem e antropofagia?

MS - A resposta que eu posso dar a essa questão é uma resposta que muito me afeta, porque, quando eu fui ao Brasil para ensinar, há 20 anos ou mais - foi nos anos 70, 40 anos, portanto -, essa questão começava a se intensificar nesse momento, e eu estava entre os que colaboraram para a discussão, porque eu falava muito de mestiçagem, etc. Então, forçosamente, quando se fala de mestiçagem, a questão é ambígua. Ela tem um lado bom e um lado ruim. Sim, eu creio que o Brasil - e eu o admiro por isso colocou esse problema e o estuda como tal. E isso é magnífico! A América do Norte, por exemplo, não enfrenta essa questão assim. Não mesmo, não mesmo. Há ainda o apartheid nos Estados Unidos. A solução para mim - e eu não poderia dizer de outra forma - ela está na educação, mas não somente na educação que consiste em dizer "você é um outro, você é um pouco outro como eu". Não. É a educação como tal. Ou seja, se você aprende chinês, você se torna um pouco chinês, se você aprende espanhol, você se torna um pouco espanhol, ou o português, etc. E, consequentemente, a aprendizagem é, ela mesma, uma mestiçagem - é isso que eu digo. Dessa forma, não somente a educação moral e humana que consiste em respeitar o outro, mas também a educação como tal, ela mesma, leva ao feito de ter a experiência de se mestiçar quando se aprende. É isso. É essa a questão. Então, quanto à antropofagia, não é de fato uma questão de devorar. Mas eu creio que há alguma coisa bastante profunda nessa analogia, porque, quando eu aprendo alguma coisa, se diz em francês - eu não sei se diz em português - "eu levei muito tempo para digerir essa informação". Se diz também em portu- 
guês, não é? E isso não é ruim. Por quê? E é essa a relação com a antropofagia - é que, definitivamente, aprendemos com o corpo. Não aprendemos apenas com a cabeça, aprendemos com todo o corpo. E é o corpo que digere, compreende? Eu acredito que há uma filosofia do corpo como uma possibilidade de metamorfose. Você sabe, quando você vê um esportista, um dançarino, um trabalhador - seja um ferreiro, um joalheiro, um pedreiro, etc. -, nunca há o mesmo gesto, sim? O corpo humano é capaz de uma infinidade de gestos. E essa infinidade de gestos mostra a que ponto ele pode aprender. Ele pode se metamorfosear. Ele pode tornar-se mestiço. Portanto, a sua questão da antropofagia eu a coloco ao lado da aprendizagem pelo corpo. E isso dá bastante importância ao corpo. Eu sempre digo, em muitos dos meus livros, que o professor principal deveria ser sempre o professor de ginástica. Porque é o professor que melhor conhece seus alunos. A diferença que há entre você, Maria Emanuela, e sua colega. Compreende o que eu digo? Não é somente devorar, é mudar o corpo inteiro. É o corpo que pode tornar-se mestiço. Eu sou ao mesmo tempo dançarino, esportista e pedreiro. Eu posso ser os três. Então, eu sou um mestiço.

M-E - No debate sobre a educação de nosso tempo se fala muito sobre a influência da cultura digital na escola. Sobretudo na França, eu tenho a impressão que essa questão é frequentemente abordada. Eu estou aqui há quatro meses e tive a oportunidade de encontrar esse debate em diferentes ambientes. Contudo, há uma cultura do livro impresso muito forte na França, bem mais que no Brasil. Eu gostaria de saber o que o senhor pensa sobre essa influência da cultura do livro digital na nossa sociedade e se há diferença entre a presença do livro digital num país com uma forte cultura do livro impresso e essa presença em um outro, no qual essa cultura do livro impresso é menos forte. 0 que o livro digital pode representar nessas duas diferentes realidades?

MS - É simples compreender isso, é muito simples. É que a Fran- 
ça é um país em que o livro impresso exerce influência há quase 1600 anos, e essa influência no Brasil é bem mais recente. É simplesmente uma questão de história. Todavia, obviamente, a cultura digital tem uma chance bem maior de entrar num país ou numa cultura na qual a influência do livro impresso é menos forte. Provavelmente haverá diferença de equilíbrio entre as duas culturas. Ou melhor, permita que eu reformule a resposta. Eu acredito que a revolução digital é a terceira revolução que nós conhecemos. A primeira revolução é a invenção da escrita. A segunda revolução é a invenção da imprensa e a terceira é o digital. A primeira invenção, da escrita, deu lugar a completas transformações. Transformações no que se refere à política, à sociedade, ao comércio, às finanças, à religião e, por fim, transformações filosóficas e pedagógicas. A Paideia grega, a pedagogia, nasceu da escritura. E a filosofia nasceu com isso. Isto é, Sócrates detesta a escrita, ele prefere falar, e Platão não fala, ele escreve. 0 jogo entre os dois é a filosofia de Platão e a invenção da escrita. No momento da invenção da imprensa, têm-se as mesmas transformações profundas, tanto na sociedade - a nova democracia, a nova maneira de trocas, o banco surge nesse momento, o cheque surgiu nesse momento - quanto na filosofia, com Montaigne. A filosofia dos livros de Montaigne, sim? E agora o digital chega e modifica em torno dos mesmos segmentos. Há uma crise financeira, é o digital; há uma crise política, é provavelmente o digital também, etc. $E$ todas as crises que nós vivemos hoje podem talvez ser consideradas ligadas à revolução digital. Então, que se tem uma crise do livro é evidente, que se tem uma crise na cultura é evidente, e é por isso que a Polegarzinha é verdadeiramente a heroína de nosso tempo. E, evidentemente, os mais velhos não a compreendem. Ou seja, a Polegarzinha é uma nova pessoa, que vive em um mundo implicado pelo digital. Um velho senhor, ele utiliza o digital como uma ferramenta exterior, ele não está no mundo digital. Há um mundo novo que está surgindo. Nesse caso, será que o livro impresso vai morrer? Eu não acredito. Não, 
porque, se eu observo as três revoluções, não é porque se tem a escrita que se parou de falar; não é porque se teve a impressão que se parou de escrever e não é porque se tem o digital que se vai parar de imprimir. Você tem uma impressora na sua casa, eu também. Você vê, logo, continuamos a imprimir. Eu acredito que há uma transformação completa. E uma das verdadeiras transformações é na pedagogia. Frequentemente perguntam a minha opinião sobre isso. Por exemplo, se o ensino on-line vai mudar completamente as universidades? É possível. É provável. Há já alguns anos que meus alunos em Stanford me dizem: "por que eu preciso pagar tão caro para ter uma coisa que eu já tenho comigo sempre?", afirmam, se referindo ao que se tem no smartphone ou no computador. É uma verdadeira questão. E, consequentemente, vemos que há uma transformação completa, até mesmo dos locais, das construções das universidades. Mas prever isso é uma coisa muito difícil. Eu não sei como prever essas mudanças. Todavia, sim. Há transformações, isso é certo. E isso vai afetar a pedagogia e talvez até mesmo a política. Eu gostaria de congelar o tempo aqui nesse momento e, então, voltar a ter sua idade para poder participar da reconstrução desse novo mundo. 